\title{
ESTUDO DA DOR E DOS EFEITOS COLATERAIS DO TRATAMENTO ONCOLÓGICO EM PACIENTES SUBMETIDOS A QUIMIOTERAPIA
}

\section{Brisa Santos Macêdo1; Maria da Conceição Andrade2; Márcio Campos Oliveira3; Agda Braga Teixeira4}

1. Bolsista PIBIC/FAPESB, Graduando em Medicina, Departamento de Saúde (DSAU), Núcleo de Câncer Oral,Universidade Estadual de Feira de Santana, e-mail: brisa.xp@hotmail.com

2. Orientador, Departamento de Saúde (DSAU), Núcleo de Câncer Oral, Universidade Estadual de Feira de Santana,e-mail: conceicao.icb@gmail.com

3. Departamento de Sáude (DSAU), Núcleo de Câncer Oral, Universidade Estadual de Feira de Santana, e-mail:marciopatologiaoral@gmail.com

4. Departamento de Saúde (DSAU), Núcleo de Câncer Oral, Universidade Estadual de Feira de Santana, e-mail:agda_braga@hotmail.com

PALAVRAS-CHAVE: Oncologia, dor, crianças.

\section{INTRODUÇÃO}

A palavra câncer vem do grego "karkínos", que quer dizer caranguejo, e foi utilizada pela primeira vez por Hipócrates, o pai da medicina. Atualmente, câncer é o nome geral dado a um conjunto de mais de 100 doenças, que têm em comum o crescimento desordenado de células, que tendem a invadir tecidos e órgãos vizinhos. Com exceção dos neurônios, que nunca se dividem, as células saudáveis crescem de maneira ordenada, se multiplicam e morrem. O crescimento das células cancerosas difere das saudáveis. Em vez de morrerem, essas células continuam a crescer incontrolavelmente, dando origem a novas células anormais. O câncer se caracteriza pela perda do controle da divisão celular e pela capacidade de invadir outras estruturas orgânicas. (INCA, 2011).

A dor é um dos fenômenos mais temidos no cenário do câncer, devido à possibilidade de seus sinais aparecerem em todo o processo do adoecer, desde o momento do diagnóstico até situações de aplicação de procedimentos terapêuticos altamente invasivos e dolorosos, e em decorrência dos efeitos adversos do tratamento cirúrgico, quimioterápico e radioterápico (SAKIROGLU, 2009). A dor também é uma experiência que acompanha os casos de recidiva ou metástase à distância, e é proporcionalmente mais intensa na medida da progressão do tumor. Os aspectos psicológicos envolvidos na dor também têm papel de destaque na configuração geral do fenômeno. A característica multidimensional da dor requer uma compreensão integral sobre a fisiologia humana em consonância com a história de vida, antecedentes familiares, processos de aprendizagem, ambiente sociocultural, dentre outros (FRUTUOSO, 2004).

De acordo com a International Association for the Study of Pain, dor é uma sensação ou experiência emocional desagradável, associada com dano tecidual real ou potencial, ou descrito nos termos de tal dano. A severidade da dor não é diretamente proporcional à quantidade de tecido lesado e muitos fatores podem influenciar a percepção deste sintoma: fadiga, depressão, raiva, medo/ansiedade doença, sentimentos de falta de esperança e amparo. Pacientes com doença avançada se deparam com muitas perdas; perda da normalidade, da saúde, de potencial de futuro. A dor impõe limitações no estilo de vida, particularmente na mobilidade, paciência, resignação, podendo ser interpretada como um "saldo" da doença que progride.

A dor oncológica ocorre em 54\% das crianças hospitalizadas e em $26 \%$ das atendidas em ambulatórios. Dentre as etiologias possíveis, ela pode ser causada pela própria doença (37\% dos casos), pelo tratamento quimioterápico $(41 \%)$ e procedimentos 
invasivos como aspiração de medula óssea (78\%) ou punção lombar (61\%). (PENA, 2008).

Os tratamentos comumente usados para o tratamento do câncer muitas vezes ocasionam reações adversas e geram situações indesejadas para a criança, como náuseas, vômitos e processos álgicos. (VALLE, 2006).

$\mathrm{Na}$ cavidade bucal os principais efeitos colaterais da quimioterapia são a mucosite, xerostomia temporária e imunodepressão, possibilitando infecções dentárias ou oportunistas. Observam-se também hemorragias gengivais decorrentes da plaquetopenia e distúrbios na formação dos germes dentários quando administrada na fase de odontogênese (MINICUCCI et al,1994). A mucosite é uma inflamação e ulceração da mucosa, frequente e dolorosa, aparecendo de 3 a 7 dias após o início da quimioterapia e pode durar vários dias. Seu primeiro sinal é a presença de eritema no palato mole, mucosa bucal, ventre da língua e assoalho bucal, seguido de edema e ulceração. Dor, queimação e desconforto estão comumente presentes, sendo intensificados durante a alimentação. (SONIS et al,1996).

\section{MATERIAL E MÉTODOS OU METODOLOGIA (ou equivalente)}

A pesquisa foi realizada no Hospital da Criança (HEC), de Feira de Santana - BA. A população foi constituída por crianças internadas no setor de oncologia, no período de agosto de 2017 a julho de 2018 com diagnóstico de câncer, idade inferior a18 anos, foram excluídos os pacientes com tumores benignos. Trata-se de um estudo epidemiológico do tipo corte transversal. Após a concordância em participar e da assinatura do TALE, foi aplicado um questionário constituído de perguntas relacionadas às características sociodemográficas, e história médica-odontológica. Posteriormente, as informações foram colocadas sob a forma de tabelas e gráficos.

\section{RESULTADOS E/OU DISCUSSÃO (ou Análise e discussão dos resultados)}

Foram examinados um total de 77 pacientes, sendo 33 do sexo masculino e 44 do sexo feminino.A faixa etária mais acometida no gênero masculino foi a de 0 a 5 anos e no feminino de 12 anos.

Tabela 1. Mucosite oral em pacientes oncológicos pediátricos do gênero masculino

\begin{tabular}{lll}
\hline & $\mathrm{n}$ & $\%$ \\
\hline Presença de mucosite oral & & \\
\hline Sim & 10 & 30,3 \\
Não & 23 & 69,7 \\
\hline Grau de mucosite oral & 05 & 50,0 \\
\hline Grau I & 03 & 30,0 \\
Grau II & 01 & 10,0 \\
Grau III & 01 & 10,0 \\
Grau IV & & \\
\hline Localização da mucosite oral & - & - \\
\hline Palato & 07 & 70,0 \\
Lábio & 02 & 20,0 \\
Língua & - & 0 \\
Assoalho bucal & 01 & 10,0 \\
Mucosa jugal & - & - \\
Trato gastrointestinal & & \\
\hline
\end{tabular}

Tabela 2. Mucosite oral em pacientes oncológicos pediátricos do gênero feminino

$\mathrm{n} \%$

\begin{tabular}{lll}
\hline Presença de mucosite oral & & \\
\hline Sim & 14 & 31,81 \\
Não & 30 & 68,18 \\
\hline
\end{tabular}

Grau de mucosite oral 


\begin{tabular}{lll}
\hline Grau I & 03 & 21,4 \\
Grau II & 01 & 7,1 \\
Grau III & 06 & 42,8 \\
Grau IV & 05 & 35,7 \\
\hline Localização da mucosite oral & & 28,5 \\
\hline Palato & 04 & 57,1 \\
Lábio & 08 & 35,7 \\
Língua & 05 & - \\
Assoalho bucal & - & 21,4 \\
Mucosa jugal & 03 & 7,1 \\
Trato gastrointestinal & 01 & 7,1 \\
Gengiva & 01 & \\
\end{tabular}

Tabela 3. Escala de dor em pacientes do gênero masculino

\begin{tabular}{lll}
\hline & $\mathrm{n}$ & $\%$ \\
\hline Presença de dor no momento da aplicação da escala & & 37,5 \\
\hline Sim & 9 & 37,5 \\
Não & 9 & 45,5 \\
Sem avaliação & 15 & - \\
\hline Intensidade da dor & & - \\
\hline 0 & - & 77,8 \\
1 & 07 & 11,1 \\
2 & 01 & 11,1 \\
3 & 01 & \\
4 & & 33,3 \\
& & 11,1 \\
Local da dor & 03 & 11,1 \\
\hline Abdômen & 01 & 11,1 \\
Acesso & 01 & 22,2 \\
Ouvido & 01 & 22,2 \\
Coluna & 02 & 22,2 \\
MMII & 02 & - \\
Gabeça & 02 & - \\
MMSS & - & \\
Ânus & - & \\
Tórax & - & \\
& & \\
\hline
\end{tabular}

Tabela 4. Escala de dor em pacientes do gênero feminino

\begin{tabular}{lll}
\hline & $\mathrm{n}$ & $\%$ \\
\hline Presença de dor no momento da aplicação da escala & & \\
\hline Sim & 10 & 22,7 \\
Não & 20 & 45,4 \\
Sem avaliação & 14 & 31,9 \\
\hline Intensidade da dor & - & - \\
\hline 0 & 01 & 10,0 \\
1 & 04 & 40,0 \\
2 & 02 & 20,0 \\
3 & 03 & 30,0 \\
4 & & 10,0 \\
& & 40,0 \\
Local da dor & 01 & - \\
\hline Abdômen & 04 & - \\
Acesso & - & 50,0 \\
Ouvido & - & 20,0 \\
MMluna & - & - \\
MMSS & 05 & 10,0 \\
Cabeça & 02 & 10,0 \\
Aarganta & - & \\
Tórax & - & \\
\hline
\end{tabular}


Na tabela 1, no gênero masculino de um total de 33 pacientes, 10 apresentaram mucosite do grau I ao IV. No gênero feminino, na tabela 2, de um total de 44 pacientes, 14 apresentaram mucosite principalmente nos graus II e IV. Sendo o lábio a localização mais prevalente em ambos os sexos. Em um total de 33 pacientes do gênero masculino, na tabela 03, 09 apresentaram manifestação de dor no momento da aplicação da escala de faces. 09 não referiram nenhum tipo de dor. Em um grau de $\mathrm{O}$ a 4, 07 pacientes $(77,8 \%)$ apresentam dor de grau 2, seguidos de 01 paciente $(11,1 \%)$ para grau 2 e 01 paciente para grau $3(11,1 \%)$. O principal local referido de dor foi abdômen, com 03 casos $(33,3 \%)$, seguido de cabeça e garganta, cada um com 02 casos (22,2\% cada). Em um total de 44 pacientes do gênero feminino, na tabela 04, 10 apresentaram manifestação de dor no momento da aplicação da escala de faces. 20 não referiram nenhum tipo de dor. Em um grau de $\mathrm{O}$ a 4, 04 pacientes (40\%) apresentam dor de grau 2 , seguidos de 03 pacientes $(30 \%)$ para grau 4 e 02 paciente para grau $3(20 \%)$. O principal local referido de dor foi MMII, com 05 casos (50\%), seguido de acesso venoso com 04 casos (40\%) e MMSS com 02 casos (20\%).

\section{CONSIDERAÇÕES FINAIS (ou Conclusão)}

Diante dos resultados, a dor se apresenta de maneira súbita em pacientes submetidos a quimioterapia. Os resultados desse estudo devem ser avaliados com cautela apesar da validação do instrumento utilizado. Trata-se de um tema complexo e de difícil abordagem, por ser um tema subjetivo e que depende da experiência e sensibilidade pessoal com a dor.

\section{REFERÊNCIAS}

FRUTUOSO, J. T., CRUZ, R. M. (2004). Relato verbal na avaliação psicológica da dor. Avaliação Psicológica, 3(2), 107-114.

INSTITUTO NACIONAL DE CÂNCER (BRASIL). ABC do câncer : abordagens básicas para o controle do câncer / Instituto Nacional de Câncer. - Rio de Janeiro: Inca, 2011.

MINICUCCI, E. M.; DIB, L. L. Sequelas odontológicas do tratamento rádio e quimioterápico em crianças. Rev Paul Pediatria, v.12, n.2, p.258-63, julho, 1994.

PENA, R.; BARBOSA, L. A. Estimulação elétrica transcutânea do nervo (TENS) na dor oncológica: uma revisão de literatura. Revista brasileira de cancerologia. N. 54, v.2, 2008.

SAKIROGLU, C. O., WOOD, C., CUNIN-ROY, C. (2009). Pain in adolescents with cancer. Bulletin du Cancer, 96(2),37-45.

SONIS,S.T.; FAZIO,R.C.; FANG,L. Princípios e prática de medicina oral. 2.ed. Rio de Janeiro: Guanabara Koogan, 1996.491 p.

VALE M. B. Analgesia adjuvante e alternativa. Revista brasileira de anestesiologia. São Paulo, V. 56, n. 5, 2006. 